\title{
INFLUÊNCIA DOS ORGANISMOS INTERNACIONAIS NAS POLÍTICAS EDUCACIONAIS: SÓ HÁ INTERVENÇÃO QUANDO HÁ CONSENTIMENTO?'
}

Esta resenha apresenta considerações acerca da obra intitulada "Influência dos organismos internacionais nas políticas educacionais: só há intervenção quando há consentimento? ${ }^{2 "}$ apresentada por Silvia Regina Canan, publicada em 2016. O livro foi desenvolvido por uma autora brasileira que realiza discussões sobre a influência de organismos internacionais nas políticas de educação brasileira, sendo ela básica ou superior. Sua organização constitui seis partes, sendo elas: o prefácio escrito por Maria de Lourdes Pinto de Almeida; a introdução; o capítulo I intitulado "Os organismos internacionais e as políticas educacionais"; o capítulo II, "O Banco Mundial no contexto da globalização: o que está implícito em suas propostas"; o capítulo III, "O Protagonismo docente nas mudanças educativas"; e as "Considerações finais".

O prefácio escrito por Maria de Lourdes Pinto de Almeida aborda as temáticas e questionamentos levantados na obra. A autora atenta para a importância da leitura deste escrito já que trata sobre a influência de organismos internacionais na educação de forma geral, tanto a básica como superior e além disso, a influência que esta minoria detêm sobre a maioria, ditando as políticas educacionais a serem desenvolvidas. As configurações da educação permitem perceber ainda o cunho mercadológico que esta assume cada vez mais, onde assim como qualquer produto, o conhecimento passa a ser visto como mais um no mercado sendo possível escolher o que ao consumidor the parece adequado, isentando o Estado desta responsabilidade que lhe seria dever. Neste prisma da empregabilidade, salienta que o princípio da educação que consiste em ir além de instruir mas libertar do conformismo e alienação fica comprometido pelo fato de suas práticas serem fundadas às necessidades do capital. Por fim, a autora resgata o título do livro e questiona: "Somente há intervenção dos organismos internacionais na educação brasileira quando há consentimento por parte do Estado Brasileiro?” (p.16).

$\mathrm{Na}$ introdução, Silvia Regina Canan contextualiza a produção do livro relatando que pertence a sua "[...] tese de Doutorado defendida no Programa de Pós-Graduação em Educação da Unisinos, intitulada Diretrizes nacionais para a formação de professores da Educação Básica: tensões e limites entre o específico e o pedagógico na formação docente" (p.19). Ao discorrer sobre o tema relata que o principal objetivo em produzir este escrito foi discutir sobre a influência que organismos internacionais (Unesco, Cepal e o Banco Mundial)

${ }^{1}$ CANAN, Silvia Regina. Influência dos organismos internacionais nas políticas educacionais: só há intervenção quando há consentimento? Campinas, SP: Mercado das Letras, 2016.

${ }^{2}$ A versão em espanhol será disponibilizada em e-book muito brevemente, pelo Consejo Latinoamericano de Ciencias Sociales (CLACSO), no sitio: http://biblioteca.clacso.edu.ar/

\begin{tabular}{l|l|l|l|l|l|l} 
() Rev. Inter. Educ. Sup. & Campinas, SP & v.2 & n.3 & p.587-590 & set./dez. 2016 & ISSN 2446-9424 \\
\hline
\end{tabular}


exercem sobre as políticas educacionais da América Latina e Caribe em troca de financiamentos de projetos em diferentes áreas. Além disso, é ressaltado a surpreendente aceitação com passividade por parte do governo diante destas imposições, o que segundo a autora, a "[...] colocou diante da necessidade de buscarmos alternativas contra essa forma hegemônica de entendê-la" (p.24).

No capítulo I, “Os organismos internacionais e as políticas educacionais" a autora menciona a relação entre as políticas educacionais com a ação dos organismos multilaterais e postula o contexto histórico em que estes órgãos externos iniciaram suas interferências. Como marco é citado a Conferência Mundial de Educação para Todos realizada em 1990 em Jomtien em que diante da situação econômica dos países da América Latina e Caribe, os órgãos internacionais passaram a se tornar os financiadores. Ressalta ainda que as intervenções sempre foram realizadas com consentimento devido em troca oferecer outras possibilidades que são consideradas positivas e favoráveis aos governos concordantes. Para elucidar suas considerações acerca do tema, a autora faz relação com o capitalismo em que tudo é transformado em mercadoria, inclusive a força de trabalho, e relata que o neoliberalismo exerce a função de reforçar o que foi desenvolvido pelo velho capitalismo em todos os âmbitos sociais, entre eles o sistema de saúde e educação. Conforme Frei Beto "Nem o Estado escapa, reduzido a mero instrumento dos interesses dos setores dominantes" (p. 41). A partir desta perspectiva, entende-se que o Estado passa a ser visto como incapaz de gerir o que lhe é de dever e por isso, abre espaço também para intervenção da iniciativa privada na educação.

O capítulo II, “O Banco Mundial no contexto da globalização: o que está implícito em suas propostas" aborda a questão da origem e finalidade do Banco Mundial, sendo este criado em 1944 com objetivo inicial de reconstrução pós-guerra, mas que com o passar do tempo teve sua atuação redefinida intervindo em diferentes áreas as quais considera pertinente. Por se colocar como uma alternativa de apoio e possibilitar a ajuda necessária para as dificuldades dos países, este organismo fornece o que é pertinente através de financiamentos, mas em troca recebe o poder de intervir nos países. Para contextualizar, o texto apresenta uma sequência cronológica das remodelagens apresentadas pelo órgão internacional e defende que os interesses do Banco Mundial sempre estiveram e estão mais voltados para o desenvolvimento econômico do que o educacional, fato este que justifica sua organização, composição e políticas propostas. Além disso, o interesse maior deste organismo é a educação básica, campo este visualizado como responsável para a diminuição da pobreza e desenvolvimento, enfatizando as políticas escolares e não educativas. Outro ponto relevante assinalado pela autora é o poder que este organismo internacional exerce sob as políticas educacionais a ponto de tornar sua ideologia legítima e determinar o modo de agir e pensar das pessoas, sem que ao menos elas se deem conta. Para discutir sobre a CEPAL/Unesco no cenário das políticas de educação, o texto relata o histórico desta que inicialmente era uma agência ideológica mas que também se transformou em um organismo internacional "[...] que passa a concordar com a política imposta pela globalização e suas políticas neoliberais”. (p. 88) Sendo assim, a educação passa a ser entendida como sinônimo de globalização e ter um

\begin{tabular}{l|l|l|l|l|l|l} 
(C) Rev. Inter. Educ. Sup. & Campinas, SP & v.2 & n.3 & p.587-590 & set./dez. 2016 & ISSN 2446-9424 \\
\hline
\end{tabular}


caráter mercadológico ressaltando a competitividade e produtividade, ou seja, o conhecimento destinado a produção de mão-de-obra. Transpondo as interferências que os organismos internacionais trazem para o Brasil, estas podem ser identificadas não somente no campo da educação mas outras reparos a níveis econômicos e sociais são propostos pelo governo neoliberal que tem seu marco representado a partir do governo de Fernando Collor de Melo.

O capítulo III, "O Protagonismo docente nas mudanças educativas" traz considerações sobre os onze itens elaborados em um documento que tratam do protagonismo docente e o interesse que a CEPAL e Unesco demonstram com relação a isso. A autora contrapõe através de interrogações a importância do docente no cenário da educação e a valorização que este recebe, sendo ela financeira ou nos demais aspectos. Um destaque interessante que a autora aponta é o direcionamento da formação docente como responsabilidade do próprio professor e não do Estado, o que novamente lhe exime do que seria seu dever. Para situar essa questão, a formação de professores é tratada por diversos documentos legais no Brasil como o Plano Nacional de Educação e Lei de Diretrizes e Bases da Educação Nacional porém os escritos indicam que a mesma dever ser procurada fora da universidade, o que direciona os profissionais a cursos de formação rápida e pode-se dizer, sem parâmetros de qualidade, o que dificulta o princípio de que o professor deve criar e recriar sua prática. Sendo assim, a educação assume um viés tecnicista em que atende os interesses do capital e não incentiva a pesquisa por exemplo, que seria mais uma de suas importantes atribuições. A não participação de professores no desenvolvimento das políticas do país e sim de economistas com a visão de mercado, reforça " [...] um modelo escolar com duas ausências fundamentais a dos professores e a da pedagogia” (p.105).

E por fim, nas "Considerações finais" é retomado o conteúdo tratado no livro para o fechamento da discussão em que considera a formação docente como importante e principal no sentido de promoção e emancipação do sujeito, mas que isso se torna contraditório pelo fato de que poucos espaços são possibilitados aos professores para discussões e debates afim de construir novas propostas para a educação. Neste sentido, “[...] as políticas instituídas na maior parte das vezes não dão conta das reais necessidades da escola e se apresentam como propostas descomprometidas com a educação" (p.109). Na questão da interferência dos órgãos internacionais, entende-se que estes direcionam a educação para os seus interesses sejam eles com diferentes objetivos, e que não é possível desconsiderar o consentimento por parte do governo, que também atinge seus objetivos, sendo a maioria mercadológicos. E por último, a autora retoma a questão da formação docente concluindo que o conhecimento do professor deve ir além de ensinar, mas que seja possível acompanhar a ciência, os clássicos e que possa aprofundar seus conhecimentos afim de contribuir com a sua formação.

A obra completa proporciona ao leitor uma maior compreensão das influências que os organismos internacionais exercem sobre a educação não somente brasileira, mas da América Latina e Caribe, bem como o percurso desenvolvido pelo capitalismo que atualmente aparece mascarado ou reformulado pelos discursos neoliberais. Ao mergulhar pelo escrito, é possível 
apreciar o histórico dessas intervenções, identificar o comportamento do Estado perante as imposições além de perceber as reformas educacionais realizadas e a importância do papel do professor neste processo. Muitos contrapontos são levantados entre as políticas e o que realmente acontece com o papel do professor que deveria ser o de promover o senso crítico dos sujeitos, mas que recebe pouco reconhecimento e possibilidades de intervenção na educação brasileira. De forma geral, conhecer este panorama nos possibilita entender o motivo de determinadas ações do governo, os caminhos que a educação percorre e a justificativa para a implantação algumas políticas educacionais que parecem incoerentes. 